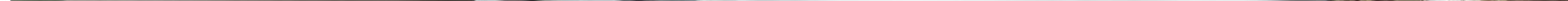




\title{
EL ARTE Y LA EDUCACIÓN EN EL CONTEXTO DE LA PANDEMIA EN EL ECUADOR
}

\section{Art and education during the pandemic in the con- text of Ecuador}

\author{
iD Juan Carlos Astudillo Sarmiento, Universidad de Cuenca (Ecuador) \\ (juan.astudillos@ucuenca.edu.ec) (https://orcid.org/0000-0002-2817-7401) \\ iD Verónica Neira Ruiz, Universidad del Azuay (Ecuador) \\ (veronicaneirar@uazuay.edu.ec) (https://orcid.org/0000-0002-3407-6893)
}

\section{Resumen}

¿La educación en artes es necesaria? Aunque la respuesta pudiese parecer obvia, este es un debate que, en más de una ocasión, se puede escuchar tanto en la academia como fuera de ella. Y las posturas son antagónicas, casi beligerantes: no es necesaria y menos en contextos de crisis (dicen algunos); en contextos de crisis es aún más necesaria (otros). El tema es urgente y sobre todo en la realidad que estamos habitando y la que empezamos a re-construir, en cuanto sociedad. Y para hacerlo, entrevistamos a tres artistas/docentes/ investigadores en y por las artes, quienes, desde su experticia, nos ayudan a hilvanar el diálogo.

\begin{abstract}
Is Education in Arts Necessary? Although the answer may seem obvious, this is a debate that on more than one occasion has been heard both in the academy and outside of it. The positions are antagonistic, almost belligerent, as it can be said that it is not necessary, and even less in crisis contexts by some; as well as being seen as even more necessary in these contexts by others. The issue is urgent and especially in the reality that we are currently living in, and the one that we are beginning to rebuild, as a society. In order to do so, we interview the artists / teachers / researchers in and through the arts who, from their own expertise, help us to weave the dialogue together.
\end{abstract}

\section{Palabras clave}

Arte, educación, entrevista, pandemia, crisis político social, Ecuador.

\section{Keywords}

Art, education, interview, pandemic, social political crisis, Ecuador. 
1.

\section{Introducción}

El arte es una función sustantiva del quehacer humano, de la expresión de las posibilidades de creación que expanden la concepción de las realidades que habita, codifica y decodifica, posibilitando la realización plena de su ser integral. El arte, además, es una forma de experiencia sobre el mundo y lo que entendemos de él y, en esa experiencia/percepción genera un conocimiento anclado al contexto de quien lo ejecuta, alcanza o adquiere: "lo que propone (el arte) es enseñar a interpretar el mundo con una mirada distinta..." (Eco, 2010, p. 415). El arte siempre será, entre otras muchas cosas, contextual y tanto en su creación como en su apreciación se ponen en juego una serie de actividades mentales, emocionales, epistémicas y sociales que hacen del acto artístico una manera de relacionarse con el mundo, con la realidad y, por supuesto, con la individualidad. Ruiz (2010) propone una serie de definiciones para el concepto de arte, que engloban distintas miradas, abarcando lo político, lo semántico, lo antropológico, lo sociológico, lo estético y lo económico, aunque, como punto de encuentro, podemos afirmar que es un fenómeno que impacta de manera directa en la construcción de las sociedades, en su episteme. El arte, para terminar, es un derecho que debe sostenerse en una sociedad sana, plural, democrática, debido a que su apreciación, promoción y accesibilidad deben ser una política de Estado que permita que la sociedad comprenda el fenómeno artístico desde todas sus aristas, apropiándose del mismo en sus diferentes posibilidades.

Por otro lado, necesariamente complementario y anclado al tema que nos convoca, pensamos en la educación (fenómeno siempre cambiante, que en estos últimos meses ha sufrido una mutación acelerada debido al contexto de la pandemia) en y por las artes en tanto urgencia que debe repensarse y plantearse en cuanto la sociedad en reconstrucción necesita las herramientas para atravesar esta experiencia; es decir, partimos de la certeza de la necesidad de acceder al hecho artístico y de la educación en sus diferentes discursos como una necesidad de vida, como un derecho de buen vivir y como una urgencia epistémica al hablar de educación formal: "La enseñanza ha reclamado la educación artística como formación integral de la persona, como vía para el desarrollo de capacidades cognitivas, expresivas y relacionales específicas" (Sánchez, 2010, p. 45).

Y es que el arte, decíamos, es una forma de entender el quehacer humano y su apropiación del mundo y, la educación, valga el lugar común, es un arte en cuanto procura la expansión de la experiencia del conocimiento a través del empoderamiento del educando y sus propias formas de relacionarse con ese conocimiento; y es desde ese punto de encuentro desde donde proponemos pensar al arte y a la educación en el contexto de la pandemia, para ponderar ese nexo obvio y complicado, porque sus fronteras están ahí sin estar, apenas dibujando una intuición que se ha debatido ampliamente sin llegar a conclusiones porque, quizá, no caben:

Cuando la educación se encuentra con el arte y la cultura, se abre una vía que brinda a niños, niñas y jóvenes la posibilidad de desarrollar todo su potencial. Una educación artística y cultural rica, con sentido, bien pensada y ejecutada, no solo ayuda a los y las estudiantes a enriquecer sus proyectos artísticos, motivándolos a utilizar de manera creativa todos los recursos locales a su alcance, sino también a formular propuestas que van en beneficio de su desarrollo (Rojas, 2016, p. 7). 
La discusión sobre la relación entre educación y arte ha sido una constante y su recorrido histórico ha sido analizado en otros espacios (ver el estudio de Jaime Ruíz: Aproximación a la epistemología de la educación artística) pero, en este espacio, nos interesa señalar la corriente conocida en Latinoamérica como "educación por el arte", que entiende el fenómeno artístico "como una estrategia para dinamizar las actividades de la escuela y llevar a cabo acciones con la comunidad" (Ruiz, 2010, p. 25), un lugar en donde "lo importante ya no es el resultado final, sino la transformación que la práctica creativa o contemplativa es capaz de causar en el ser humano" (Viñao, 2021, p. 92), en cuanto horizonte para la propuesta de este escrito; es decir, una corriente orientada, a lo largo del siglo XX y desde políticas educativas dirigidas

a la educación por el arte (...) desde postulados procedentes de la autoexpresión creativa, del reconstruccionismo, de la expansión de la Bauhaus, del racionalismo científico (que fomentará la educación artística basada en las disciplinas) o de la más actual Escuela de la Cultura Visual (Choin y Moya, 2017, p. 2).

Y nos invitamos, entonces, a pensar en qué hace el arte en un contexto de encierro en donde, quizá, reclama un espacio central en las nuevas configuraciones sociales/familiares que hemos ido tejiendo, a tientas, en donde el tiempo vacío y el espacio de reclusión nos obligan a buscar aristas, puntos de fuga, anclajes para comprender o, mejor, para rebasar las limitaciones de un mundo nuevo que nos reta a seguir siendo, sin todas las distracciones que el mundo de fuera nos tenía previstas. El encierro, a no dudarlo, nos ha obligado a mirar hacia dentro y en ese nuevo ver el arte puede/debe/intenta ser una "tabla de náufrago" que, en una sociedad líquida (como dijera Bauman), se convierte en refugio y sentido. ¿Es necesario, nos preguntamos, en este contexto, re-pensar en la educación en y por las artes? ¿Desde dónde podemos entender esa pregunta y cuáles son los derroteros que marcan la duda, sus posibles respuestas y la forma de abordarlas?

Para procurar respuestas o nuevas preguntas, quizá, hemos decidido acudir a expertos educadores en artes/artistas y establecer un diálogo que nos permita construir, abriendo un debate necesario en estos nuevos tiempos en donde todo debe ser vuelto a debatir.
Nuestros invitados son: Virginia Gamez: Licenciada en Historia del Arte y Magíster en Didáctica de la Expresión Plástica y Visual, por la Universidad Complutense de Madrid, Doctora en Didáctica de las Artes y Humanidades, por la Universitat de Barcelona; actualmente es docente titular en Pedagogía de las Artes, en la UNAE. Santiago Harris: Psicólogo clínico, UDA; Diploma superior en Salud y Terapias Integrativas, UASB; Maestría en Artes Escénicas UFBA-Brasil; miembro fundador del grupo Clowndestinos; ex docente en la Universidad del Azuay, Universidad de Cuenca y Universidad de las Artes; actualmente en formación en el instituto Internacional Somatic Experiencing ${ }^{\circledR}$ - Uruguay; y Gabriel Noriega: Bachelor en Ciencias Políticas por Sciences-Po Paris y Master en Investigación en Artes y lenguajes por la EHESS (Paris), ex-docente de la Universidad Nacional de Educación y del CECIB "Cacique Tumbalá", de Engabao.

Por lo dicho, tendimos un diálogo para poner en crisis la necesidad o no de la enseñanza/aprendizaje del arte en el contexto actual ecuatoriano, atendiendo la crisis sociopolítica, económica y sanitaria que estamos afrontando.

\section{2.}

\section{Metodología}

Nuestro enfoque aborda la entrevista en cuanto herramienta/técnica de investigación cualitativa, que permite un diálogo asincrónico que, establecido a través del discurso escrito, brinda la posibilidad del pensar y sopesar la palabra por lo que la valoramos para acceder al pensamiento procesado y asertivo de los entrevistados. Taguenca y Vega (2012) definen esta herramienta en tanto su

función es interpretar los motivos profundos que tienen los agentes a la hora de actuar o pensar de determinado modo con respecto a distintos problemas sociales (...) la entrevista necesita de la libre expresión del entrevistado, lo que quiere decir que él mismo debe manifestar sus intereses, creencias, deseos y valores tal y como los siente (...) este aspecto es fundamental, sin ello las entrevistas carecerían de valor informativo (...). (p. 60) 
De la misma manera Sanmartín Arce (2003) asegura que lo que busca el entrevistador es resolver sus propias dudas, es decir, se cuestiona a sí mismo antes de proponer a los actores porque sabe que existe una diferencia entre lo que conoce y lo que quiere conocer.

Desde una perspectiva lingüística, se diría que

la conversación es algo así como la culminación de la dimensión del habla; es el lugar en el que se ponen a prueba todas las capacidades pragmáticas de la lengua y de los hablantes y, al mismo tiempo, es el campo en el que las finalidades dan sentido a la situación. (Jitrik, 2006, p. 19).

y que, en una entrevista/diálogo es en donde se ejecutan esas capacidades en su máxima expresión.

El tipo de entrevista con el que trabajamos es la estructurada o enfocada, ya que las preguntas, establecidas en un orden determinado, fueron enviadas a todos los sujetos (Díaz, 2013).

De esta manera, el alcance de las entrevistas que generamos, en algo que podríamos llamar "multientrevistas asincrónicas", propone preguntas enfocadas que procuran respuestas reflexivas que permitan analizar los discursos/enunciados y la información que exponen.

Es decir: los tres entrevistados recibieron un mismo cuestionario y nosotros hemos enhebrado las respuestas para procurar ese diálogo asincrónico entre las diferentes voces, señalando sus puntos de encuentro o desencuentro y la valiosa información que nos permite, de alguna manera, tender puentes de comprensión para estos fenómenos y sus tiempos complejos y delicados.

Es indispensable recalcar como afirma Beaud (2018) la imposibilidad de una postura neutral del entrevistador (o entrevistadores en este caso), como el mito de la "neutralidad", principalmente porque el investigador tiene un móvil específico que es aquello que busca encontrar. De lo expuesto se colige que esta investigación es de tipo cualitativo, descriptivo, anclada en el método Delphi, en tanto "técnica de obtención de información, basada en la consulta a expertos de un área, con el fin de obtener la opinión de consenso más fiable del grupo consultado" (Reguant-Álvarez y Torrado-Fonseca, 2016, p. 3).

3.

\section{Desarrollo}

La propuesta es, para generar el diálogo del que hemos platicado, articular las voces de los entrevistados a partir de las respuestas generadas. Para hacerlo, expondremos las preguntas y las respuestas articuladas en un mismo cuerpo.

De esta manera, la primera pregunta/paraguas, que procuró generar un lugar para partir o, quizá, establecer una frecuencia para la plática, fue: ¿Es importante pensar en la educación por el arte, en el contexto actual de pandemia y crisis sociopolítica ecuatoriana?, ¿por qué? y ¿para qué?

Harris asegura que es a través de las artes y sus diferentes manifestaciones como encontramos "el sustento emocional, sensitivo, contendedor de memoria y de comportamientos de las diversas culturas" (comunicación personal, 29 julio 2020), y que con estas podemos crear un pensamiento crítico garantizando así la educación por el arte "entendida como el desarrollo de sensibilidades y modos de relación-comunicación que atraviesan y trascienden lo que conocemos comúnmente como arte" (comunicación personal). Gamez afirma que la educación por el arte no solo es importante sino necesaria, y que la pandemia nos ha replanteado el deber de reinventarnos como sociedad, no únicamente por la afección a nivel económico, social y ecológico, sino por la certeza de que "la educación tiene un potencial único para lanzar nuevas miradas y cuestionar de una manera creativa la crisis en la que estamos sumergidos" (comunicación personal, 20 junio 2020). Noriega, por su parte, explica que "donde la virulencia de la Covid es aprovechada por el entreguismo neoliberal para arrasar con el sector público, es importante pensar, pero sobre todo defender la educación por el arte (y habría que agregar "pública, gratuita y de calidad")" (comunicación personal, 24 julio 2020). Gamez, Noriega y Harris (comunicación personal, 29 julio 2020) aseguran que la educación por el arte permitirá la visión crítica, la resilien- 
cia, la creatividad, la reinvención, el cuestionamiento, la provocación que permitirá a los estudiantes de las próximas generaciones enfrentar crisis, defender una postura, reinterpretar, como menciona Noriega "el vínculo entre el arte y la sociedad y que entienda que es en el ámbito cultural, en la reflexión sobre la relación del hombre con su entorno (...), que se juega nuestro destino". Encontramos en estas respuestas un vínculo para con la concepción del conocimiento como ejercicio crítico catalizado por la herramienta artística que, además, se expresa en el currículo ecuatoriano de 2016, que "exige del docente mayor formación especializada y proyección didáctica para hacer efectiva esa libertad de acción académica de la que ahora dispone, imposible sin un acervo cultural y procedimental afianzados que garanticen la calidad de los procesos educativos" (Choin y Moya, 2017, p. 3).

En cuanto a la segunda pregunta, que procuraba poner en crisis la relación educación/arte/virtualidad, en estos términos: ¿Cómo abordar la educación en artes en cuanto ejercicio estético y crítico de la realidad, en un contexto virtual que, al menos desde el lugar común, se antoja una herramienta frívola, carente de la emocionalidad del contacto y el compartir humanos? Nace de la percepción dicotómica de, por un lado, la ausencia del contacto y lo que significa y, por otro, la oportunidad de afrontar la autonomía (aprendizaje autónomo) en el entorno virtual. En palabras de García Albarido (2020) y parafraseando a Deleuze: "la aparición de una autonomía requiere de una tensión que nace del nosotros, del aprender juntos, del hazlo conmigo y no del hazlo como yo" (p. 279).

Harris, desde su perspectiva como estudioso del método $\mathrm{SE}^{\mathrm{TM}}$-Somatic Experiencing, señala que para el aprendizaje las personas integramos y organizamos varios niveles de experiencia "que se relacionan entre sí todo el tiempo: Sensaciones, Imágenes (memorias), Comportamientos, Afectos y Significados". Pese a que el contacto humano es irremplazable, la virtualidad se superpone como un entorno más, y considera que las clases en línea tienen la oportunidad de generar "un tipo de contacto y cercanía que dé contención y acompañamiento, siempre y cuando sean utilizadas estrategias que generen un ambiente seguro, de confianza y de placer de aprender" (Harris, (comunicación personal, 29 julio 2020). Tanto Harris como Gamez (comunicación personal, 20 junio 2020) se cuestionan cómo la virtualidad ha afectado al pro- ceso de enseñanza, en el que recalcan la desconfianza y la pasividad, especialmente debido "a la escasa preparación de docentes y estudiantes, también sobre el cuestionamiento del acceso a internet y a la tecnología en sectores económicamente desfavorecidos y, por supuesto, sobre los resultados de aprendizaje", $\mathrm{y}$ que ante todo es indispensable cuestionarse sobre el rol de las tecnologías en la educación y comprender que "la enseñanza virtual como un acto político/ estético, tanto desde la perspectiva de los estudiantes como la de los docentes, permitiría generar una nueva perspectiva sobre el mundo que nos rodea" (Gamez, comunicación personal, 20 junio 2020).

Una de las dificultades que se han encontrado los docentes en la virtualidad es trabajar con una gran cantidad de estudiantes que no encienden sus cámaras, por la posible idea de distancia que esto genera en el acto comunicacional y por los procesos que confrontan al docente en estos escenarios nuevos:

esta proyección que evoca la pantalla al ver solo una imagen con un fondo en negro, a veces es desoladora. Sin duda, es una imagen que en un primer momento bien puede fomentar esa idea de que las aulas virtuales son un entorno de aprendizaje frívolo, carente de emocionalidad del contacto y el compartir humanos. Sin embargo, desde una perspectiva política/estética, creo que estas pantallas apagadas hablan mucho, porque en realidad, apagar la cámara es una acción muy significativa, por parte del estudiante. Y justamente como acto estético, yo veo la acción de apagar la cámara como un símbolo que no me habla para nada de un acto de pasividad e indiferencia. Para mí, es un acto que habla mucho de lo que los estudiantes no quieren mostrar o de lo que consideran deben esconder, dejando muy claro lo lejos que el mundo educativo está de las realidades sociales que vive cada estudiante (Gamez, comunicación personal, 20 junio 2020).

Difícil es pensar sobre un fenómeno al estar en él, por supuesto, y la realidad virtual en la educación nos ha demostrado que debemos aprender a construir en la marcha. Las reflexiones que esta pregunta nos invita hacen eco de lo que Fontana (2020) manifiesta, a propósito del comentario de Inés Dussel sobre un meme que, parafraseando a Magritte y su pipa-no-pipa, ponía en crisis la idea de una computadora que no es es- 
cuela (esto, claro, antes de la pandemia); la reflexión continúa, en palabras de la especialista:

Quizás en el futuro, si mejora sus funcionalidades y sus envites, la computadora -o sus sucedáneospueda ser una escuela. Pero lo será si logra condensar algunos de los sentidos de la escuela: autonomía, alteridad, conversación intergeneracional, estudio como atención al mundo, calidad y cuidado de la presencia del mundo (Dussel, citada en Fontana, 2020, p. 202).

La tercera pregunta, que parte de una aproximación a la propuesta de Bourdieu (2003) y la sociología de la cultura, cuando diferencia las necesidades "primarias" de la "necesidad cultural" y su precariedad, invisible para el contexto en donde no se dinamiza, quiso ser directa y pensar si tiene o no sentido la educación por el arte en esta crisis: ¿Para qué educar en artes en un país/sociedad en plena crisis? Las respuestas:

Harris recuerda que el país siempre ha estado en crisis y que esta es la consecuencia de "un desequilibrio social globalizado que oscila entre una creciente necesidad de seguridad, comodidad y sentido de pertenencia y una desconexión de otras comunidades, otras especies y la naturaleza"; pero ante todo recuerda que los espacios que permiten promover la reflexión crítica - principalmente- sobre el arte y la cultura, logran generar "difusión de saberes, cohesión social, promoción de valores comunitarios, respeto a la diversidad, apropiación de la identidad, conexión con la naturaleza y reflexión colectiva" (comunicación personal, 29 julio 2020). Además, la educación por el arte se evidencia en las relaciones sociales, costumbres, expresiones creativas, rituales, entre otros, que forman parte de la producción de conocimiento en donde se asientan las bases de la sociedad, por lo que asegura que es una inversión que se verá a corto y a largo plazo debido al rol preponderante de la cultura y las artes en la economía, al ser un sector en continuo desarrollo. Este momento histórico se convierte en una oportunidad para hacer cambios, como señala Noriega: "tenemos el deber de imaginar en conjunto nuevas maneras de estar en el mundo" (comunicación personal, 24 julio 2020), como el abordaje a la educación, entendiendo los enormes esfuerzos que han realizado los docentes de todos los niveles para adaptar contenidos y mantener la educación a flote, y que a partir de estas reflexiones debemos "observar si estamos educando para mantener y perpetuar una sociedad de consumo desconectada de la historia, de la diferencia de clases y del ecosistema" (Noriega, comunicación personal, 29 julio 2020), ya que a través de la educación por el arte se pueden "fortalecer prácticas y valores que expandan la sensibilidad humana para transformar las crisis en oportunidades desde una mirada crítica" (Harris, comunicación personal, 29 julio 2020). Noriega asegura que

hablar de educación en artes es hablar de las capacidades críticas y creativas que tiene una sociedad, de la capacidad para diseñar la realidad y el mundo en el que queremos existir. Educarnos en el arte es educarnos en la ilusión de un mejor mañana. (comunicación personal, 24 julio 2020)

La cuarta pregunta procuró abordar la realidad labo$\mathrm{ral} /$ social, incierta siempre y proyectada, ahora, sobre un futuro aún más contingente: Artistas (o docentes) por el arte: ¿qué oportunidades laborales encuentran en el mundo que estamos empezando a entender?

La pregunta se sostiene en la crisis que rebasa lo sanitario y evidencia la fragilidad de un sistema que procura, al parecer, sostenerse en la radicalización de las formas que, precisamente, han negado la "importancia" del arte y sus expresiones: el racionalismo rancio del método y la utilidad del conocimiento como fin último del saber. Boaventura de Sousa Santos (2020) señaló los riesgos potenciales de esta forma de entender la educación, ejemplificándolos en las "cuarentenas intermitentes" y "los piratas del capitalismo universitario", que reducen la docencia a los derechos de distribución de los cursos online que entiende, nos parece, como la vertiginosidad de un tiempo de "mucha política disfrazada de tecnología" ${ }^{1}$ (en Dussel et al., 2020, p. 296).

Harris explica que los esquemas tradicionales (familia, profesión, comunidad, entre otros) están siendo reconfigurados en diversas posibilidades. Gamez recuerda la complejidad del mundo laboral en el que continuamente aparecen necesidades que descubren profesiones, o "un sinfín de trabajos que aún ni se han

1. El ensayo Tecnologías, cuerpos y resistencia: todo eso que decimos los artistas, de Andrés García Albarido, aborda y aclara estas nociones. 
inventado o imaginado" (Gamez, comunicación personal, 20 junio 2020), y es en este panorama en donde artistas y educadores deben reinventarse, pero no cerrarse ante la idea de que la única salida laboral está en las aulas. El arte no solo se aprende en la academia y para trabajar en ella es indispensable el cuarto nivel de estudios, pero muchos artistas, pese a su talento y conocimiento, no tienen la oportunidad de trabajar como docentes, y las condiciones laborales para todo el gremio suelen ser precarias, porque principalmente dependen de fondos públicos: hay ausencia de contratos, inestabilidad de ingresos y en la docencia no universitaria, bajos salarios que provocan pluriempleo. Es por esto que las oportunidades laborales dependen de los gestores, productores e investigadores, donde el terreno puede ser fértil especialmente en trabajos colaborativos: "en el encuentro con tecnología, ciencia, comunidades, instituciones, salud, naturaleza, entre otros; como una forma de generar recursos desde propuestas vinculantes y creativas" (Harris, comunicación personal, 29 julio 2020); sobre esto Gamez asegura que los equipos transdisciplinares son cada vez más necesarios; y es por esto que las universidades tienen un papel importante: "las generaciones de nuevos artistas y docentes deben estar preparados para generar vínculos, diálogos y consensos en un mundo post pandemia" (comunicación personal, 29 julio 2020).

La última pregunta quiso confrontar las nociones de producción artística en el contexto actual: ¿Cómo entender el concepto de "producción" desde el campo del arte, en el contexto neoliberal que viven muchas de las naciones del continente?

Gamez reflexiona sobre el término producción porque se lo entiende desde una definición muy cerrada, a partir de la idea de la producción neoliberal, que alude a la percepción desde la necesidad de tener una profesión para triunfar en el ámbito laboral, y es por esto que la cultura, el arte y la educación deben ir por el mismo camino y así cambiar el paradigma "en términos de utilidad y productividad, el sector cultural y artístico. Para ello, la educación es la llave de todo" (Gamez, comunicación personal, 20 junio 2020). Noriega cree que el economicismo es la razón por la que no se comprende la importancia vital de las artes en una sociedad ya que "para el lugar común, las artes son una cuestión secundaria, dispensable, o en el mejor de los casos, son consideradas como bienes sun- tuarios" (comunicación personal, 24 julio 2020). Esta percepción tendría, siguiendo a Noriega, al menos dos errores fundamentales: los países que han decidido apostar a las industrias creativas han logrado beneficios económicos muy altos, como sucede con la industria musical en Colombia o Brasil o el cine en Argentina; y en segundo lugar porque "el arte produce ciertos valores que escapan al entendimiento simplista de ciertos economistas" (Noriega, comunicación personal, 24 julio 2020). Estos valores se relacionan con la capacidad crítica que puede desarrollar una sociedad y que, sin ellos, "la transformación del mundo seguirá el guion frenético en el que estamos embarcados" (Noriega, comunicación personal, 24 julio 2020). Es por estas razones que asegura que el Ecuador y Latinoamérica deben crear proyectos políticos colectivos y populares que "generen las capacidades de proponer otros futuros, más soberanos, más feministas, más ecologistas, donde podamos ser más felices" para avanzar realmente al Sumak Kawsay.

El valor de uso sobre los objetos y prácticas artístico culturales, nos parece, está presente en estas respuestas, que parecieran comulgar con la propuesta de García (2020) cuando afirma que "los objetos culturales constituyen ejercicios (Sloterdijk, 2021) y conforman técnicas de sí (Foucault, 1990), capaces de empoderar a los sujetos atencionales por incluirlos en amplios tejidos de intercambio simbólico..." (p. 283). La importancia de dimensionar el acto artístico y educativo y sus objetos en cuanto depositarios de un poder simbólico que yace en su posibilidad de acceso, de interpretación.

\section{4.}

\section{Conclusiones}

¿Qué hacemos, entonces, ante esta realidad en la que el arte y su formación se han convertido en lo desechable? Si pensamos en la educación y el camino de cambios que va descubriendo a partir del confinamiento y las desigualdades sociales que evidenció, sabemos que la educación por el arte queda aún más relegada. Ventajosamente el arte y sus quehaceres en tanto formas de crear imaginarios e intercambio social no han parado, pese a que, para 
los artistas, gestores culturales, educadores de arte, mediadores, entre otros, las condiciones laborales se han visto no solo afectadas, sino que, en la mayoría de los casos, anuladas. A pesar de esto, sostenemos, junto a los entrevistados, que la educación por el arte nos permite deconstruir, disrumpir, dudar y poner en crisis la realidad que nos rodea, y que en el contexto actual, probablemente más que nunca, es indispensable para la construcción de un futuro plural, crítico, emancipatorio y empoderado.

Para terminar y en resonancia con la pregunta que García (2020) realizó en su estudio "Tecnología, cuerpos y resistencia: todo eso que decimos los artistas", cuando se cuestionaba el por qué los docentes artistas construyen su locus de enunciación, indefectiblemente, desde una posición crítica a lo social, suscribimos la respuesta que encuentra el escritor y docente argentino cuando apela al "carácter democratizante de la mediación cultural" que trasciende "cierta identificación economicista del ocio como consumo o prosumo", situándose en la "posibilidad constructiva (...) capaz de contestar la captura mediática de la atención y, quizá, la degradación del trabajo en empleo" (p. 282).

\section{Referencias}

Astudillo, J., Neira, V. (2020). Educación en artes: una necesidad urgente. Diario El Mercurio. https://bit.ly/3ig7xtm

Beaud, S. (2018). El uso de la entrevista en las ciencias sociales. En defensa de la "entrevista etnográfica". Revista Colombiana de Antropología. 54, 175-218.

Bourdieu, P. (2003). Campo de poder, campo intelectual: itinerario de un concepto. Quadrata.

Díaz-Bravo, Laura, Torruco-García, Uri, Martínez-Hernández, Mildred, \& Varela-Ruiz, (2013). La entrevista, recurso flexible y dinámico. Investigación en Educación Médica, 2, (7), pp. 162-167
Dussel, I.; Ferrante, P.; Pulfer, D. (2020). Pensar la educación en tiempos de pandemia: entre la emergencia, el compromiso y la espera. CLACSO.

Eco, U. (2010). Historia de la belleza. Debolsillo.

Grunberg, G.; Schweisguth, E. (1996) Bourdieu et la misère. Une aproche réductionniste., Revue Française de Science Politique 46. páginas

Margarita. (2013). La entrevista, recurso flexible y dinámico. Investigación en educación médica, 2(7), 162-167. https://bit.ly/3kNmCV3

Reguant-Álvarez, M. y Torrado-Fonseca, M. (2016). El método Delphi. REIRE, Revista d'Innovació $i$ Recerca en Educació, 9 (1), 87-102. 10.1344/reire2016.9.1916

Rojas Durán, P. (2016). Caja de herramientas para la educación artística. Consejo Nacional de la Cultura y las Artes. Chile.

Ruiz Solórzano, J. (2010). Principales corrientes teóricas de la educación artística. https://bit.ly/3upfoeP

Sánchez, A. (2010) Arte y educación. https://bit.ly/3ulzVzk

Sanmartín Arce, R. (2003). Observar, escuchar, comparar, escribir. Ariel.

Taguenca, J. A., Vega, M. (2012) Técnicas de investigación social. Las entrevistas abierta y semidirecta. Revista de investigación en Ciencias Sociales y Humanidades. Nueva Época. 1 (1). https://bit.ly/3EVpJ5k 
